\title{
DADOS SOOBRE A BIOLOGIA DO TRIATOMA ARTHURNEIVAI NO SUDESTE DO ESTADO DE SÃO PAULO, BRASIL (HEMIPTERA, REDUVIIDAE) (1)
}

\author{
Oswaldo Paulo FORATTINI (2) \\ Edmundo JUAREZ (2) \\ Ernesto Xavier RABELLO (3)
}

\begin{abstract}
Assinala-se o encontro de focos naturais do Triatoma arthurneivai Lent e Martins, 1940, na localidade de Itupararanga, Municipio de Votorantim, no Estado de São Paulo. Os ecótopos apresentaram as mesmas caracteristicas já assinaladas anteriormente em regiōes vizinhas, ou sejam, as de espacos localizados entre lascas de pedras de «granito róseo». 0 triatomineo apresentou-se associado com lagartos Tropidurus torquatus Wied. mas, no laboratório, mostrou acentuada avidez por sangue de camundongos albinos. Por outro lado, a infecção experimental com Trypanosoma cruzi (cêpa F-1) foi obtida com facilidade. Em vista dos dados coletados, os autores permitem-se tecer considerações sôbre a possibilidade dêsse hemíptero vir a desempenhar algum papel transmissor, na natureza.
\end{abstract}

o Triatoma arthurneivai foi descrito por LENT \& MARTINS ${ }^{5}$ (1940) a partir de um exemplar fêmea obtida após evolução, em laboratório, de forma imatura coletada em localidade da Serra do Cipó, Município de Jaboticatubas, no Estado de Minas Gerais. Contudo, além dessa, os mencionados autores capturaram várias outras ninfas de estádios diferentes. Isso deu lugar, concomitantemente, à realização de algumas observações sôbre o seu comportamento. No que concerne ao campo, mencionou-se o encontro de várias espécies de roedores que freqüentavam os locais de captura. Estes eram constituí- dos por amontoados de pedras soltas, de determinado muro, situado perto de habitações. A altitude local era de 1300 metros. Além disso, em condições de laboratório, verificou-se que os insetos alimentavam-se em pombos com facilidade. Apresentaram, inclusive, certos hábitos predadores, pois algumas das ninfas foram observadas sugando formas análogas de blatídeos Blaberinae, de espécie comumente encontrada no local. Finalmente, as pesquisas das casas na proximidade e da infecção natural por tripanossomos, resultaram completamente negativas.

Recebido para publicação em 27-9-1968.

(1) Do Departamento de Epiđemiologia da Faculdade de Higiene e Saúde Pública da Universidade de São Paulo, e do Departamento de Zoologia da Secretaria da Agricultura do Estado de São Paulo. Trabalho realizado com o auxílio parcial da Fundação de Amparo à Pesquisa do Estado de São Paulo. (C. Med. 67/416)

(2) Do Departamento de Epidemiologia da FHSP.

(3) Do Departamento de Zoologia da Secretaria da Agricultura. 
FORATTINI, O. P.; JUAREZ, E. \& RABELLO, E. X. - Dados sôbre a biologia do Triatoma arthurneivai no sudeste do Estado de.

Rev. Saúde públ., S. Paulo, 2(2):186-193, dez. 1968.

Depois disso, a presença dessa espécie sòmente voltou a ser assinalada de maneira esporádica. Ainda no Estado de Minas Gerais, foi ela encontrada em Santa Rita de Caldas. Nessa região, foram obtidas algumas formas adultas em domicílios (Pellegrino ${ }^{6}$, 1951) e em biótopos semelhantes ao já anteriormente descrito, ou seja, entre pedras soltas (BARRETo ${ }^{2}$, 1966). Os outros encontros dizem respeito ao Estado de São Paulo e, de maneira específica, à região do Município de Sorocaba. Alí inicialmente, foi registrado o achado de raros exemplares adul. tos em habitações e anexos da cidade do mesmo nome e arredores (CorrêA, AlVes \& Pascale ${ }^{4}, 1962$; Alkes \& Noda ${ }^{\text {, }}$ 1964). Pouco tempo depois, nessa mesma área, Corrêa, Alves \& NodA ${ }^{3}$ (1965) encontraram os focos naturais dêsse triatomíneo em biótopo do mesmo tipo do já conhecido anteriormente. Estava êle localizado entre lascas de pedra do assim chamado "granito róseo" ou "granito de Itu", onde notaram a presença de ovos, ninfas e adultos. Dessa maneira, puderam realizar algumas observações, assinalando a provável associação alimentar com lagartos da espécie Tropidurus torquatus Wied. No laboratório, verificaram a alimentação dêsse hemíptero com sangue de galinha. Ao lado disso, no mesmo trabalho, os mencionados autores descrevem o ôvo, e fornecem dados adicionais sôbre formas imaturas e adultas.

Em resumo, os dados atualmente disponíveis sôbre o Triatoma arthurneivai evidenciam, pela sua escassez, que se trata de espécie ainda mal conhecida, principalmente no que concerne aos seus hábitos. No decorrer do segundo semestre de 1967 tivemos a oportunidade de deparar com área de apreciável extensão, onde encontramos numerosos focos naturais dessa espécie. Isso deu-nos o ensejo de levar a efeito algumas observações cujo relato constitui o objetivo dêste trabalho.

$A$ região - A área onde foram encontrados ecótopos com a presença de $T$. arthurneivai situou-se na localidade deno- minada Itupararanga, no Município de Votorantim do Estado de São Paulo. Encontra-se ela na vizinhança do Município de Sorocaba, ao qual antes pertencia, e onde foram levadas a efeito as observações descritas no parágrafo anterior.

Essa área encontra-se às margens de reprêsa artificial, de mesmo nome, e a altitude local é um tanto maior do que a média regional que é de 550 metros. A região é formada por campos ondulados cobertos de vegetação predominantemente rasteira e arbustiva e poucas árvores, e onde se nota a emergência de aglomerados de pedras. Estas são constituídas por rochas de alaskito, conhecido como "granito róseo", e formado essencialmente por feldspato potássico e quartzo (CoRRÊA, Alves \& NodA $\left.{ }^{3}, 1965\right)$. O aspecto dessas pedras é freqüentemente laminar, com a presença de numerosas lascas entre as quais formam-se espaços preenchidos com vegetação è matéria orgânica. As figuras $n .^{\circ} 1,2,3$ e 4 , mostram algưns dêsses aspectos.

Esses terrenos margeiam a citada reprêsa e são de propriedade da Companhia Light \& Power. As casas que alí se encontram são as que servem de residência ao pessoal empregado na operação e manutenção dessas instalações.

Caracteristicas dos ecótopos - De posse das informações obtidas por CoRRÊA, Alves \& Noda ${ }^{3}$ (1965), levamos a efeito a pesquisa de triatomíneos em habitáculos semelhantes aos inicialmente descritos por êsses autores. Assim sendo, procuramos remover as lascas de pedra e examiná-las cuidadosamente (Figs. 3 e 4). A maior parte dos exemplares foi encontrada na face inferior da placa, correspondente ao teto do espaço subjacente. $\mathrm{Na}$ maioria das vêzes, os insetos foram vistos escondendo-se nas anfractuosidades da superfície rochosa (Fig. 5), de onde se locomoviam sòmente após serem importunados (Fig. 6). 
FORATTINI, O. P.; JUAREZ, E. \& RABELLO, E. X. - Dados sôbre a biologia do Triatoma arthurneivai no sudeste do Estado de.. Rev. Saúde públ., S. Paulo, 2(2):186-193, dez. 1968.
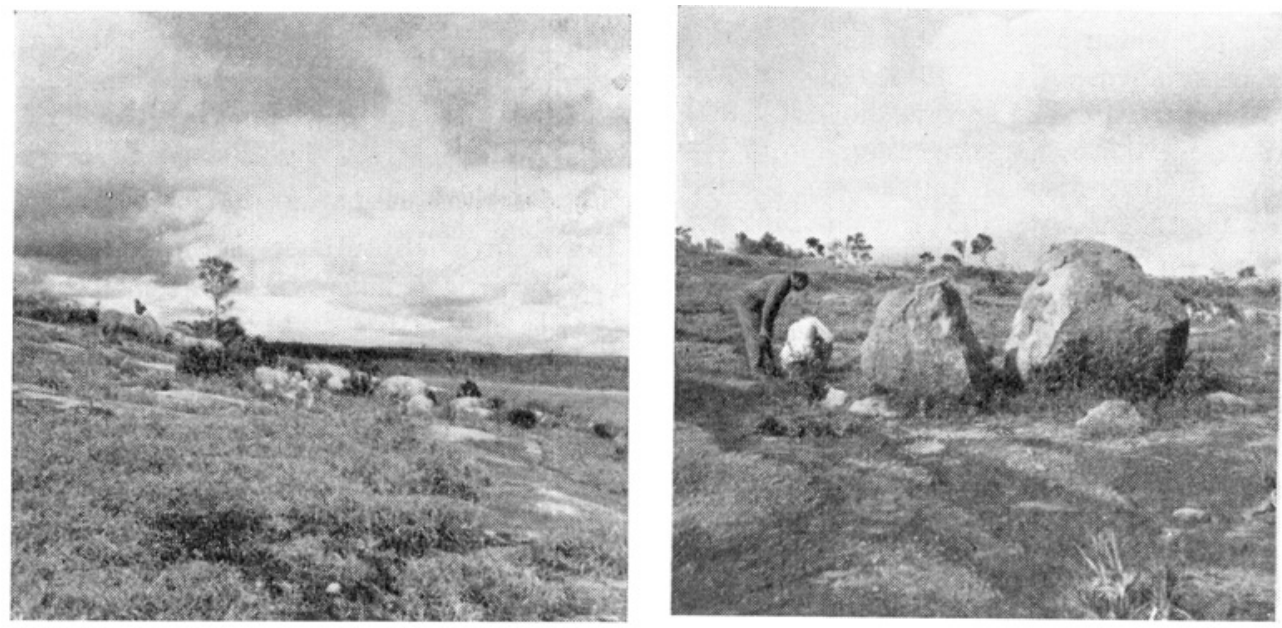

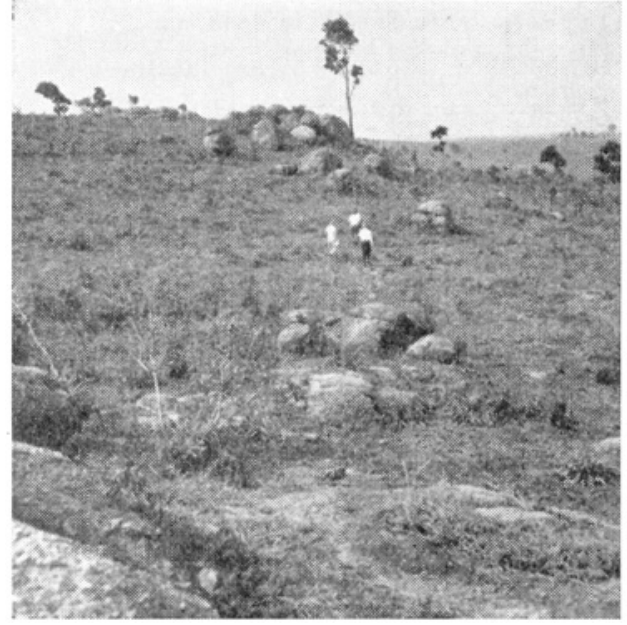

Figs. 1 e 2 - Aspectos dos campos ondulados da região Itupararanga, com os aglomerados de pedras de "granito róseo".

A possível associação com lagartos Tropidurus torquatus foi sugerida por CoRRÊA, Alves \& NodA ${ }^{3}$ (1965), ao notarem êsses autores a freqüente presença de tais répteis nas proximidades dos criadouros. Em nossas observações verificamos o mesmo fato. Assim é que pudemos sur-

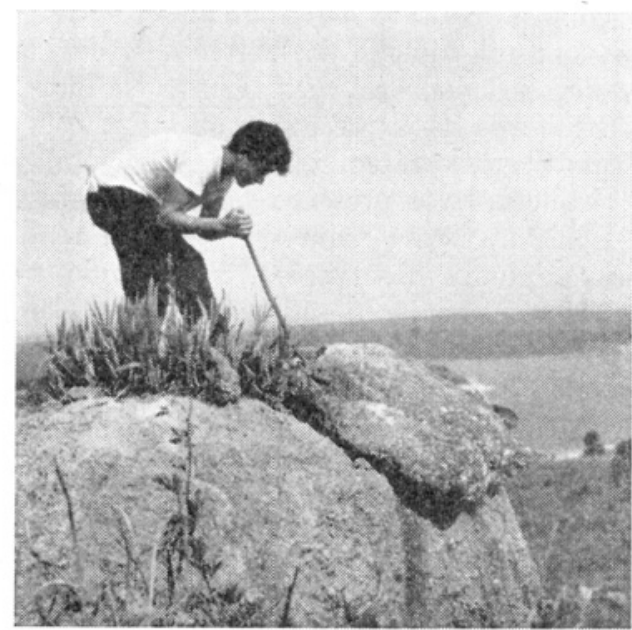

Figs. 3 e 4 - Pedras de "granito róseo" com lascas sob as quais se encontram os ecótopos com $T$. arthurneivai. No segundo plano da Fig. ne 4 observa-se trecho da Reprêsa de Itupararanga.

preender a ocorrência dêsses animais debaixo de quase tôdas as placas levantadas, onde se encontravam triatomíneos. Isso tornou a sua captura relativamente fácil. Trata-se de lagartos de pequeno porte $e$, com apreciável freqüência, encontram-se as suas posturas, constituídas por pequeno número de ovos (Figs. 7 e 8 ). 
FORATTINI, O. P.; JUAREZ, E. \& RABELLO, E. X. — Dados sôbre a biologia do Triatoma arthurneivai no sudeste do Estado de.. Rev. Saude públ., S. Paulo, 2(2):186-193, dez. 1968.

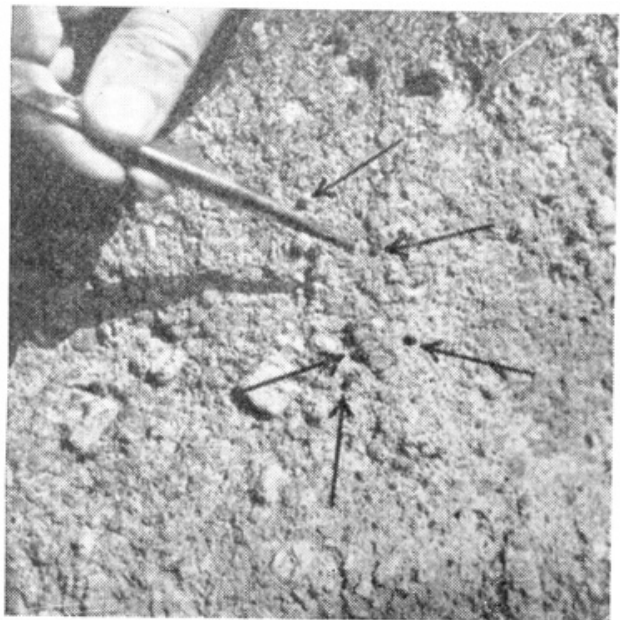

Fig. 5 - Face Inferior de uma das lascas de pedra, mostrando a presença de várias ninfas de T. arthurneivai, escondidas nas anfractuosidades da superficie.

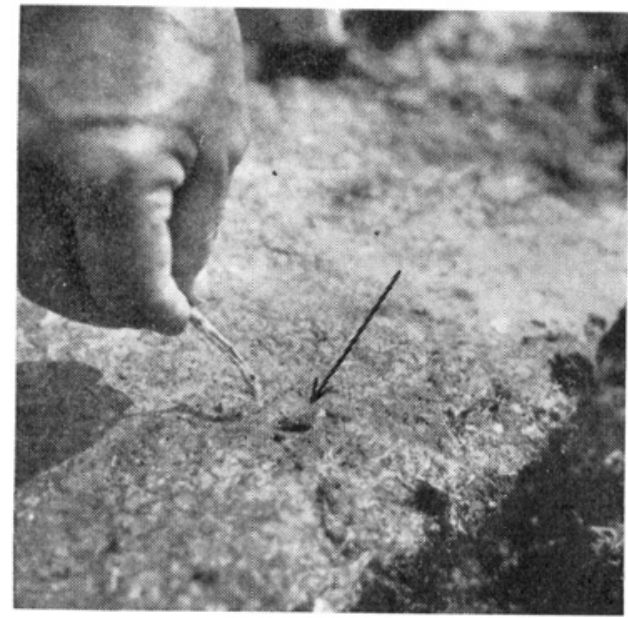

Fig. 6 - Ninfa de T. arthurneivai locomovendo-se após ser desalojada de seu esconderijo.

Observaçōes de campo - $\mathrm{Na}$ região supradescrita e durante o período de XI. 1967 a I. 1968 levamos a efeito várias coletas, deslocando para isso, diversas lascas do "granito róseo". Como resultado,

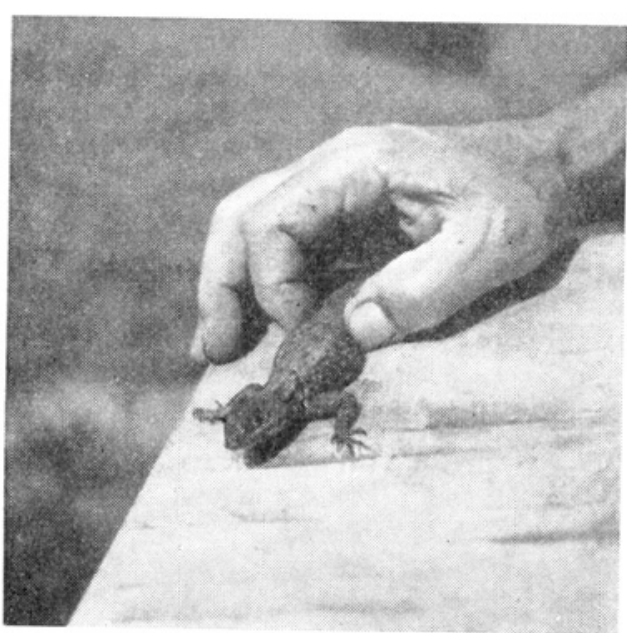

Fig. 7 - Exemplar de Tropidurus torquatus.

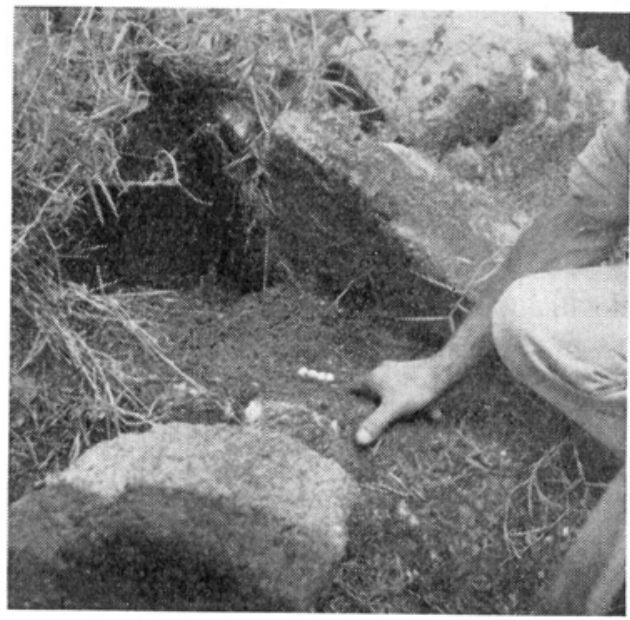

Fig. 8 - Espaco subjacente a uma lasca de pedra removida, onde foram encontradas ninfas de $\boldsymbol{T}$. arthurneivai, cascas de ovos dêsse hemiptero, e ovos férteis (assinalados) de Tropidurus torquatus.

conseguimos obter o total de 248 exemplares de Triatoma arthurneivai dos quais, 221 eram ninfas e 27 adultos. Estes últimos, pois, representaram apenas cêrca de $11,0 \%$ do total de espécimens coleta- 
FORATTINI, O. P.; JUAREZ, E. \& RABELLO, E. X. - Dados sôbre a biologia do Triatoma arthurneivai no sudeste do Estado de.

Rev. Saúde públ., S. Paulo, 2(2):186-193, dez. 1968.

dos. Além disso, se considerarmos que as ninfas menores, por serem de mais difícil visualização, passam comumente desapercebidas, essa percentagem deverá ser certamente menor ainda. No entanto, foi freqüente o encontro de cascas de ovos eclodidos, indicando a presença anterior de adultos no ecótopo. Tais resultados assemelham-se aos registrados em relação a outras espécies de triatomíneos as quais, quando encontradas em seus focos naturais, sempre compareceram com pequeno número dessas formas (BARRETTo ${ }^{2}, 1966$ ).

Durante as pesquisas tivemos também oportunidade de obter alguns exemplares de $T$. arthurneivai recentemente engurgitados. Esse fato sempre coincidiu com a presença de Tropidurus no habitáculo, o que nos fêz lògicamente pensar na hipótese já mencionada de que tais répteis fossem as fontes do repasto sanguíneo. Como não dispúnhamos de meios de identificar o sangue ingerido através a realização das reações de precipitina pensamos obter algum indício mediante o exame do conteúdo intestinal. Dessa maneira, foram feitos esfregaços de sangue obtido de 16 ninfas encontradas engurgitadas e o exame microscópico revelou a presença de hemácias nucleadas. Ao lado disso, levamos a efeito algumas observações de laboratório as quais serão descritas em parágrafo adiante.

No que concerne ao ambiente domiciliar, foi possível o encontro de seis exem. plares adultos, nas residências dos funcionários locais. Dêsses espécimens, cinco foram obtidos nas casas e um em chiqueiro anexo. Os moradores foram concordes em afirmar que, com certa freqüência, encontravam êsses insetos em suas casas. Como porém utilizavam largamente inseticidas comerciais, com exceção daquele encontrado no chiqueiro, os demais triatomíneos foram achados já mortos.

Quanto ao Tropidurus torquatus, levamos a efeito algumas observações para a pesquisa de possivel associação alimentar dêsses lagartos em relação àquêles triatomíneos. Com êsse objetivo, foram exa- minados os conteúdos intestinais de 23 exemplares. Como resultado, foram encontrados, com freqüência, restos de artrópodes. Contudo, em nenhum dêles pudemos encontrar aspectos que nos autorizassem a afirmar, com segurança, que pertenciam a exemplares de $T$. arthurneivcii.

Por outro lado, tanto nos triatomíneos como nos répteis, nunca foi possível evidenciar a presença de infecção natural por tripanossomos.

Observações de laboratório - Em condições laboratoriais, o material supradescrito foi utilizado para tentar esclarecer alguns aspectos da biologia do Triatoma arthurneivai. Para tanto, foram levadas a efeito algumas provas com o objetivo de observar a alimentação e a infecção experimental por tripanossomos.

Alimentação - A alimentação em aves foi, desde o início, assinalada em relação a pombos e galinhas (Lent \& Martins ${ }^{5}$, 1940; Corrếa, Alves \& Noda $\left.{ }^{3}, 1965\right)$. Todavia, em virtude do que pudemos observar no campo, o nosso interêsse orientou-se na verificação da possibilidade dêsse triatomíneo exercer a sua hematofagia em outros vertebrados. Com essa finalidade, empregamos lotes de vários exemplares aos quais oferecemos, para sugar, espécimens de Tropidurus e de camundongos albinos.

Em uma série de experiências foram constituídos 4 lotes de ninfas. A 3 dêles foi oferecida a oportunidade de sugarem lagartos Tropidurus. Quanto ao outro, procedeu-se da mesma forma em relação a camundongos. $O$ s resultados encontram-se resumidos na Tabela 1.

Como se pode verificar, por tais resultados, foi muito maior o número de exemplares que sugaram camundongo do que o daquêles que sugaram lagarto. Essa diferença torna-se ainda mais evidente, ao se considerar que o tempo gasto foi muito menor para o primeiro (30 minutos) do que para o segundo (3 a 4 horas). 
FORATTINI, O. P.; JUAREZ, E. \& RABELLO, E. X. - Dados sôbre a biologia do Triatoma arthurneivai no sudeste do Estado de. Rev. Saúde públ., S. Paulo, 2(2):186-193, dez. 1968.

T A B E L A 1

Tentativas de alimentação de Triatoma arthurneivai em Tropidurus torquatus e em camundongo albino

\begin{tabular}{r|c|c|c|c|c}
\hline Lote & Fonte & $\begin{array}{c}\text { no de } \\
\text { ninfas }\end{array}$ & Tempo & Sugaram & $\begin{array}{c}\text { Não } \\
\text { sugaram }\end{array}$ \\
\hline 1 & T. torquatus & 8 & $3 \mathrm{~h}$ & $\mathbf{8}$ \\
2 & T. torquatus & 51 & $4 \mathrm{~h}$ & $\mathbf{1 1}$ & 40 \\
3 & T. torquatus & 27 & $4 \mathrm{~h}$ & 2 & 25 \\
4 & Camundongo & 24 & $30 \mathrm{~min}$ & 22 & 2 \\
\hline
\end{tabular}

Em outra série de experiências foram utilizados lotes, aos quais eram fornecidas ambas as fontes de repasto sanguíneo, sucessivamente. Em primeiro lugar colocou-se o lagarto. Após tempo que variou de 3 a 4 horas, ofereceu-se camundongo aos exemplares que não tinham sugado aquêle. Os resultados constam da Tabela 2.

Da mesma forma, verifica-se que os indivíduos que não sugaram Tropidurus prontamente o fizeram em relação a camundongo.

Como já se mencionou atrás, a capacidade predatória dêste triatomíneo foi assinalada já nas observações iniciais de Lent \& Martins ${ }^{5}$ (1940). Êsses autores notaram algumas ninfas sugando bla- tídeos que habitavam o mesmo ecótopo. Em nossas observações de laboratório, tivemos também a oportunidade de verificar fato semelhante, porém em relação a canibalismo. Assim é que pudemos observar uma ninfa de $30^{\circ}$ estádio sugando um exemplar adulto recém mudado. Este, aliás, apresentava-se em situação precária, não tendo conseguido sobreviver. A mencionada sucção processou-se principalmente através os artículos antenais da prêsa.

Infecção experimental - Na tentativa de obtermos a infecção experimental por Trypanosoma cruzi, utilizamos ratos silvestres da espécie Akodon arviculoides (Winge). Para tanto, aproveitamos a oportunidade de termos capturado uma fêmea grávida, procedente do Bairro da

T A B E L A 2

Tentativas de alimentação sucessiva, de Triatoma arthurneivai em Tropidurs torquatus e em camundongo albino

\begin{tabular}{c|c|c|c|c|c|c|c|c}
\hline \multirow{2}{*}{ Lote } & \multicolumn{2}{|c|}{ No de } & \multicolumn{3}{c|}{ T. torquatus } & \multicolumn{3}{c}{ Camundongo } \\
\cline { 2 - 10 } & ninfas & adultos & Tempo & Sugaram & $\begin{array}{c}\text { Não } \\
\text { Sugaram }\end{array}$ & Tempo & Sugaram & $\begin{array}{c}\text { Não } \\
\text { Sugaram }\end{array}$ \\
\hline 1 & 13 & - & $3 \mathrm{~h}$ & 1 & 12 & $30 \mathrm{~min}$ & 8 & 4 \\
2 & 20 & - & $3 \mathrm{~h}$ & 0 & 20 & $30 \mathrm{~min}$ & 15 & 5 \\
3 & 11 & - & $4 \mathrm{~h}$ & 2 & 9 & $30 \mathrm{~min}$ & 3 & 6 \\
4 & - & 11 & $4 \mathrm{~h}$ & 0 & 11 & $30 \mathrm{~min}$ & 11 & 0 \\
\hline
\end{tabular}


FORATTINI, O. P.; JUAREZ, E. \& RABELLO, E. X. - Dados sôbre a biologla do Triatoma arthurneivai no sudeste do Estado de.. Rev. Saúde públ., S. Paulo, 2(2):186-193, dez. 1968.

Ilha, Município de Salto de Pirapora, no Estado de São Paulo. Esse animal revelou-se negativo, tanto à hemoscopia como ao xenodiagnóstico. Após chegar ao laboratório, deu origem a ninhada constituída por quatro espécimens. Estes foram inoculados no dia 19.I.68, por via intraperitoneal, com fezes positivas de Triatoma infestans, infectados com a cêpa F-l, procedente da mesma área. Nessa oportunidade, os roedores estavam com 15 dias de idade.

A 30.I.68, os animais inoculados revelaram-se positivos à hemoscopia. Nessa ocasião procedeu-se ao xenodiagnóstico, utilizando para tanto, 6 ninfas de $2 .^{\circ}$ estádio de Triatoma arthurneivai. A seguir, foram novamente alimentadas nos mesmos animais, sucessivamente, nos dias $5,14 \mathrm{e}$ 23.II.68 e 13.III.68. Nesta última alimentação, as fezes expelidas mostraram-se positivas para formas evolutivas de tripanossomos.

Depois disso os insetos foram mantidos em laboratório, com alimentações espaçadas levadas a efeito sôbre camundongos albinos. A 23. VIII. 68 um dêsses exemplares, já no estádio adulto, foi sacrificado e triturado. A suspensão dêsse material foi inoculada por via intraperitoneal em 6 camundongos recém-nascidos. A primeira hemoscopia positiva dêsses animais foi observada a 31.VIII. 68.

Dessa maneira, o Triatoma arthurneivai revelou-se capaz de se infectar e albergar formas evolutivas do $T$. cruzi, durante apreciável espaço de tempo.

Comentários - $\mathbf{O}$ encontro de focos naturais, apreciàvelmente extensos, do Triatoma arthurneivai, ensejou a possibilidade de levar a efeito algumas observaçōes sôbre a biologia dêsse triatomíneo.

Pôde-se confirmar as características principais do ecótopo, primeiramente assinaladas por CorrêA, Alves \& NodA ${ }^{3}$ (1965). Nesses locais, o número de ninfas sempre sobrepujou, de muito, o de formas adultas. Nấo se dispõem ainda de explicaãões satisfatórias para êsse fato o qual, aliás, se repete com freqüência em relação aos focos naturais de outras espécies dêsses insetos (BARRETTo $^{2}$, 1966). Poderia ser admitida a hipótese de que os adultos teriam a tendência de abandonar o habitáculo, logo após a muda. Com isso procurariam cumprir a finalidade de dispersão e instalação de novos focos alhures. Além disso, em virtude dessa maior mobilidade, essas formas seriam mais fàcilmente notadas e, conseqüientemente, atingidas pelos predadores.

No que concerne a possíveis associações alimentares, desde o início chamou a atenção a freqüente presença, nos focos, de lagartos Tropidurus torquatus. Embora fôssem encontradas ninfas engurgitadas com sangue, muito provàvelmente dêsse vertebrado, em condiçōes laboratoriais o triatomíneo mostrou-se bastante ávido por sangue de camundongos. Esse fato nos permite aventar a hipótese de que, na natureza, êle possa vir a se servir de roedores e colonizar-se em ecótopos onde ocorram tais mamíferos. $\mathrm{Na}$ realidade, as observações realizadas até o momento não permitem concluir definitivamente se a associação alimentar entre o $T$. arthurneivai e os mencionados lagartos, corra por conta de uma preferência daquêle por êstes ou vice-versa. Na área por nós pesquisada existem várias espécies de roedores e outros mamíferos. Todavia, até agora, não nos foi possível encontrar o triatomíneo associado com qualquer dêsses animais.

Com relativa freqüência, os indivíduos adultos foram assinalados nas habitaçōes humanas da regiāo. Isso, a nosso ver, constitui mais um argumento que reforça a hipótese do possível papel de dispersão, por parte dêsses alados.

Finalmente, em condições de laboratório, o Triatoma arthurneivai infectou-se fàcilmente pelo Trypanosoma cruzi. Essa infecção foi conseguida após passagem prévia do parasito num rato silvestre da espécie Akodon arviculoides. Com isso, tivemos a pretenção de verificar se o tria. 
FORATTINI, O. P.; JUAREZ, E. \& RABELLO, E. X. - Dados sôbre a biologia do Triatoma arthurneivai no sudeste do Estado de. Rev. Saúde públ., S. Paulo, 2(2):186-193, dez. 1968.

tomíneo poderia desempenhar o papel de transmissor da infecção entre prováveis hospedeiros naturais do flagelado. Os resultados foram eloquentes e, pelo menos, teòricamente, essa. possibilidade não pode ser afastada.

Em resumo, embora ainda não tenhamos encontrado o Triatoma arthurneivai naturalmente infectado, deve-se admitir a possibilidade dessa espécie vir a desempenhar o papel de transmissora na natureza. Para tanto, contribui acentuadamente a facilidade com que ela se alimenta em roedores e adquire a infecção experimental.

\section{S U M M A R Y}

An area with natural foci of Triatoma arthurneivai Lent \& Martins, 1940, is recorded at the place of Itupararanga in the county of Salto de Pirapora, São Paulo State, Brasil. These foci were represented by ecotopes placed between sliced stones, similar to the ones previously described in surrounding regions. An association with lizards Tropidurus torquatus Wied. it was suspected to be of feeding nature. Nevertheless the triatomids sho. wed to eat quickly and intensively white mice, under laboratory conditions. Beside this, the experimental infection by Trypanosoma cruzi was easily obtained. These data led the authors to suspect that T. arthurneivai may play some transmission role in nature.

\section{REFERÊNCIAS BIBLIOGRAFICAS}

1. ALVES, U. P. \& NODA, J. - Os transmissores da doença de Chagas da região de Sorocaba, Estado de São Paulo, Brasil. Arq. Hig., São Paulo, 29(101):141-157, set., 1964.

2. BARRETTO, M. P. - Aspectos da epidemiologia da tripanossomose americana, infeção com focos naturais, com especial referência à região nordeste do Estado de São Paulo. Ribeirão Prêto, 1966. (Tese para Cátedra - Fac. Farm. Odont. Ribeirão Prêto.)

3. CORREA, R. R.; ALVES, U. P. \& NODA, J. - Nota sôbre o Triatoma arthurneivai. Seu criadouro extradomiciliar ( $\mathrm{He}$ miptera, Reduviadae), Rev. bras. Malar., $17(2 / 3)$ :217-234, abr./set., 1965.

4. CORREA, R. R.; ALVES, U. P. \& PASCALE, G. - Presença do Triatoma arthurneivai em Sorocaba (Hemiptera, Reduviidae). Rev. paul. Med., 60(3):267, mar., 1962.

5. LENT, H. \& MARTINS, A. V. - Estudos sôbre os triatomideos do Estado de Minas Gerais, com descrição de uma espécie nova. Rev. Entomol., 11:877-886, 1940.

6. PELLEGRINO, J. - Transmissores da doença de Chagas no Estado de Minas Gerais. Rev. Ass. méd. Minas Gerais, 2(1): 43-66, maio, 1951. 